\title{
Combined value of red blood cell distribution width and global registry of acute coronary events risk score on predicting long- term major adverse cardiac events in STEMI patients undergoing primary PCI
}

\author{
Xue-Wei Chang 1,2,*, Shou-Yan Zhang ${ }^{2, *}$, Hao Wang ${ }^{2}$, Ming-Ming Zhang ${ }^{2}$, Wei-Feng \\ Zheng ${ }^{2}$, Hui-Fang $\mathrm{Ma}^{2}$, Yun-Fei Gu${ }^{2}$, Jing-Han Wei ${ }^{1}$ and Chun-Guang Qiu ${ }^{1}$ \\ ${ }^{1}$ Department of Cardiology, The First Affiliated Hospital of Zhengzhou University, Zhengzhou, Henan 450052, China \\ ${ }^{2}$ Department of Cardiology, Luoyang Central Hospital Affiliated to Zhengzhou University, Luoyang, Henan 471009, China \\ *These authors contributed equally to this work
}

Correspondence to: Chun-Guang Qiu, email: 70771282@qq.com

Keywords: myocardial infarction, red cell distribution width, coronary artery, percutaneous coronary intervention

Received: August 23, $2017 \quad$ Accepted: December 03, $2017 \quad$ Published: January 10, 2018

Copyright: Chang et al. This is an open-access article distributed under the terms of the Creative Commons Attribution License 3.0 (CC BY 3.0), which permits unrestricted use, distribution, and reproduction in any medium, provided the original author and source are credited.

\section{ABSTRACT}

The combined value of RDW and GRACE risk score for cardiovascular prognosis in ST-segment elevation myocardial infarction (STEMI) undergoing primary percutaneous coronary intervention (PCI) has not been fully investigated. This study was designed to explore the combined value of RDW and GRACE risk score on predicting longterm major adverse cardiac event (Mace) in STEMI patients undergoing primary PCI. This study included 390 STEMI patients. The primary endpoint at the $(33.5 \pm 7.1)$ months follow-up was composed of cardiac death and nonfatal myocardial infarction. The relationship between clinical parameters and clinical outcomes was evaluated using Cox regression model and receiver operating characteristic (ROC) analysis. Mace occurred in 126 (32.3\%) patients including 54 (13.8\%) cardiac deaths and 72 $(\mathbf{1 8 . 5} \%)$ nonfatal myocardial infarctions. Patients in Mace group had significantly higher RDW and GRACE score than the patients in non-Mace group. According to the Cox model, RDW and GRACE score were the most important independent predictors of Mace and cardiac death. The best cut-off value for RDW to predict the occurrence of primary events was $13.25 \%$ (AUC $=0.694,95 \%$ CI:0.639-0.750, $P<0.001$ ) and that for GRACE score was 119.5 (AUC $=0.721,95 \%$ CI:0.666-0.777, $P<0.001$ ). The combination of RDW and GRACE score were more valuable (AUC $=0.775,95 \%$ CI: 0.727-0.824, $P<0.001$ ). Kaplan-Meier analysis provided significant prognostic information with the highest risk for cardiac death (Log-Rank $X^{2}=24.684, P<0.001$ ) in group with both high RDW (>13.25\%) and high GRACE score ( $>119.5)$. The combination of RDW level and GRACE score may be valuable and simple independent predictors of Mace and cardiac death in STEMI patients undergoing primary PCI. They may be useful tools for risk stratification and may indicate long-term clinical outcomes.

\section{INTRODUCTION}

Red blood cell distribution width (RDW) is a parameter of circulating erythrocytes measured by hematology analyzer. It is calculated automatically or manually by formula and expressed as a percentage. Recent studies have shown that RDW played a key role in cardiovascular disease progression through various physiological and pathological manifestations [1-3]. Increased attention has been focused on the predictive and prognostic value of RDW in patients with coronary heart disease, heart failure, atrial fibrillation, aortic valve replacement surgery, acute pulmonary embolism and cerebral infarction [4-10]. Elevated RDW is associated 
with a higher risk of perioperative stroke/transient ischaemic attack and death in patients undergoing heart valve surgery [11]. Moreover, high RDW is also associated with cardiovascular events and mortality in patients after myocardial infarction [12].

The Global Registry of Acute Coronary Events (GRACE) risk score has been developed to assess the prognosis of patients with acute coronary syndromes (ACS) [13]. It was calculated with admission variables, including age, heart rate, systolic blood pressure, Killip class, ST-segment deviation, serum creatinine, cardiac markers and cardiac arrest. Detection of a high GRACE risk score is associated with poor prognosis [14]. European Society of Cardiology (ESC) and American Heart Association (AHA) guidelines emphasize the important prognostic value of GRACE risk score, and recommend its use for risk evaluation routinely [15-16].

Understanding whether RDW and GRACE score play an important role in predicting the prognosis of ST-segment elevation myocardial infarction (STEMI) would assist in greater accuracy with respect to the risk stratification of STEMI patients and would also provide the opportunity for early interventions to improve patient prognosis. No previous study has evaluated the combined value of RDW and GRACE risk score in predicting the major adverse cardiac event (Mace) in STEMI patients, nor its association with Mace in the long term followup. Therefore, we attempt to explore the prognostic value of the two parameters separately and combinedly in predicting the cardiovascular outcomes and mortality in STEMI patients undergoing primary percutaneous coronary intervention (PCI).

\section{RESULTS}

\section{Demographic variables and baseline clinical characteristics}

During the follow-up period (33.5 \pm 7.1 months), a total of 126 Mace were recorded, including 54 (13.8\%) cases of cardiac deaths, and $72(18.5 \%)$ cases of nonfatal myocardial infarction. There were no significant difference in clinical characteristics, including demographic variables, angiographic information and several biochemical parameters between Mace group and nonMace group. However, Mace occurred most frequently in the patients who had a higher Killip classification, higher GRACE score level, and higher concentration of RDW and hsCRP, as compared to non-Mace patients (Table 1).

\section{Associations between demographic variables and RDW}

No significant association has been found between either RDW (r $=0.063, P=0.216)$ or hsCRP ( $\mathrm{r}=0.007$, $P=0.895)$ and GRACE score. However, a remarkable correlation was observed between hsCRP and RDW $(\mathrm{r}=0.198, P<0.001)$ (Figure 1).

\section{Cox regression analysis for Mace and cardiac death}

Univariate analysis of data showed that RDW, GRACE score, hsCRP and Killip class were strongly associated with Mace. Moreover, RDW, GRACE score, hsCRP, LDL-C, and anterior infarction were significantly associated with cardiac death (Table 2). A multivariate Cox regression model showed that RDW $(\mathrm{HR}=1.735$, 95\% CI 1.439-2.091, $P<0.001)$, GRACE score (HR $=$ $1.022,95 \%$ CI $1.017-1.028, P<0.001)$, hsCRP $(\mathrm{HR}=$ $1.056,95 \%$ CI $1.025-1.088, P<0.001)$, current smoker $(\mathrm{HR}=1.668,95 \% \mathrm{CI} 1.166-2.387, P=0.005)$, anterior infarction $(\mathrm{HR}=1.673,95 \%$ CI 1.163-2.407, $P=0.006)$, and angina history ( $\mathrm{HR}=0.522,95 \%$ CI $0.329-0.829$, $P=0.006)$ were associated with Mace. Moreover, RDW $(\mathrm{HR}=1.562,95 \%$ CI $1.174-2.078, P=0.002)$, GRACE score $(\mathrm{HR}=1.015,95 \%$ CI 1.007-1.023, $P=0.001)$, hsCRP $(\mathrm{HR}=1.054,95 \%$ CI $1.007-1.103, P=0.024)$, LDL-C (HR $=1.499,95 \%$ CI 1.092-2.059, $P=0.012)$, and anterior infarction $(\mathrm{HR}=2.221,95 \% \mathrm{CI} 1.268-3.892$, $P=0.005)$ were independent predictors of cardiac death (Table 2). After adjusting for age, current smoker, anterior infarction, angina history, and LDL-C, RDW (HR $=1.702$, 95\% CI $1.436-2.017, P<0.001) /(\mathrm{HR}=1.546,95 \% \mathrm{CI}$ $1.198-1.994, P<0.001)$ and GRACE $(\mathrm{HR}=1.019,95 \%$ CI $1.014-1.023, P<0.001) /(\mathrm{HR}=1.015,95 \%$ CI $1.008-$ $1.023, P<0.001)$ score were still significantly associated with Mace and cardiac death.

\section{Diagnostic value of RDW and GRACE score for Mace}

ROC analysis was conducted to determine the cutoff value of RDW and GRACE score for the prediction of the occurrence of Mace. The cutoff of RDW was $13.25 \%$, with $63.5 \%$ sensitivity and $69.3 \%$ specificity (AUC $=$ $0.694,95 \%$ CI $0.639-0.750, P<0.001$ ), And the cutoff of GRACE score was 119.5 , with $69.8 \%$ sensitivity and $67.4 \%$ specificity (AUC $=0.721,95 \%$ CI $0.666-0.777$, $P<0.001)$. Combining RDW and GRACE risk score yielded a much more valuable predictive value $(\mathrm{AUC}=$ $0.775,95 \%$ CI: $0.727-0.824, P<0.001)$ with sensitivity and specificity achieving $72.2 \%$ and $73.5 \%$ successively (Figure 2).

\section{The Kaplan-Meier survival analysis for cardiac death}

Patients were further divided into four groups according to the cutoff value of RDW (13.25\%) and GRACE score (119.5): low RDW $(<13.25 \%)$ and low GRACE score $(<119.5)$ group $(n=136)$, low RDW $(<$ 
Table 1: Demographic variables and baseline clinical characteristics

\begin{tabular}{|c|c|c|c|}
\hline Characteristics & $\begin{array}{c}\text { MACE group } \\
\quad n=126\end{array}$ & $\begin{array}{c}\text { Non-MACE group } \\
n=264\end{array}$ & $P$ value \\
\hline Age, years & $62.5 \pm 11.5$ & $61.5 \pm 11.2$ & 0.424 \\
\hline Gender, male & $100(79.4)$ & $195(73.9)$ & 0.237 \\
\hline $\mathrm{BMI}, \mathrm{Kg} / \mathrm{m}^{2}$ & $23.7 \pm 2.98$ & $23.8 \pm 3.58$ & 0.844 \\
\hline Initial heart rate, beats/min & $74.5 \pm 15.0$ & $74.2 \pm 11.2$ & 0.844 \\
\hline Current smoker & $65(51.6)$ & $115(43.6)$ & 0.137 \\
\hline Hypertension & $61(48.4)$ & $147(55.7)$ & 0.178 \\
\hline Diabetes mellitus & $25(19.8)$ & $66(25.0)$ & 0.260 \\
\hline Family history & $32(25.4)$ & $54(20.5)$ & 0.271 \\
\hline \multicolumn{4}{|l|}{ Medication at discharge } \\
\hline Aspirin & $125(99.2)$ & $262(99.2)$ & 1.000 \\
\hline Clopidogrel & $125(99.2)$ & $263(99.6)$ & 0.542 \\
\hline Statins & $124(98.4)$ & $261(98.9)$ & 0.660 \\
\hline Beta-blocker & $102(81.0)$ & $212(80.3)$ & 0.880 \\
\hline ACEI/ARB & $87(69.0)$ & $189(71.6)$ & 0.606 \\
\hline Diuretic & $42(33.3)$ & $84(31.8)$ & 0.765 \\
\hline Angina history & $25(19.8)$ & $67(25.4)$ & 0.228 \\
\hline Anterior infarction & $65(51.6)$ & $112(42.4)$ & 0.089 \\
\hline Killip class $\geq 2$ & $42(33.3)$ & $47(17.8)$ & 0.001 \\
\hline Number of diseased vessels & & & 0.136 \\
\hline 1-vessel disease & 86 & 161 & \\
\hline 2-vessel disease & 33 & 94 & \\
\hline 3-vessel disease & 7 & 9 & \\
\hline Number of stents per patient & $1.24 \pm 0.58$ & $1.28 \pm 0.63$ & 0.490 \\
\hline Gensini score & $49.1 \pm 26.9$ & $46.5 \pm 26.2$ & 0.374 \\
\hline LVEDD, mm & $48.5 \pm 4.8$ & $47.5 \pm 6.5$ & 0.145 \\
\hline LVEF, \% & $58.8 \pm 8.3$ & $59.9 \pm 9.3$ & 0.264 \\
\hline Creatinine, umol/L & $71.8 \pm 20.2$ & $72.1 \pm 20.4$ & 0.915 \\
\hline Uric acid, $\mathrm{mmol} / \mathrm{L}$ & $312.0 \pm 101.0$ & $305.8 \pm 96.0$ & 0.556 \\
\hline Potassium, mmol/L & $4.12 \pm 0.52$ & $4.19 \pm 0.44$ & 0.232 \\
\hline Total cholesterol, $\mathrm{mmol} / \mathrm{L}$ & $4.42 \pm 1.03$ & $4.33 \pm 1.07$ & 0.438 \\
\hline Triglyceride, $\mathrm{mmol} / \mathrm{L}$ & $1.64 \pm 0.94$ & $1.78 \pm 1.14$ & 0.249 \\
\hline HDL-C, mmol/L & $1.09 \pm 0.24$ & $1.12 \pm 0.28$ & 0.429 \\
\hline LDL-C, mmol/L & $2.57 \pm 0.76$ & $2.42 \pm 0.76$ & 0.076 \\
\hline HsCRP, g/L & $9.61 \pm 5.05$ & $6.96 \pm 4.89$ & $<0.001$ \\
\hline White blood cell count & $9.90 \pm 3.79$ & $9.57 \pm 2.49$ & 0.302 \\
\hline Hemoglobin, g/L & $137.0 \pm 17.3$ & $137.6 \pm 18.9$ & 0.794 \\
\hline Platelet count & $223.5 \pm 62.0$ & $212.4 \pm 60.1$ & 0.092 \\
\hline RDW, \% & $13.5 \pm 0.99$ & $12.9 \pm 0.87$ & $<0.001$ \\
\hline GRACE score & $133.0 \pm 31.3$ & $112.3 \pm 23.0$ & $<0.001$ \\
\hline
\end{tabular}

Values are presented as mean \pm SD or $\mathrm{n}(\%)$. Abbreviations: ACEI: Angiotensin-converting enzyme inhibitor, ARB: Angiotensin receptor blocker, LVEDD: Left ventricular end-diastolic dimension, LVEF: Left ventricular ejection fraction, HDL-C: High-density lipoproteincholesterol, LDL-C: Low-density lipoprotein-cholesterol, hsCRP: Hypersensitive C reactive protein, RDW: Red blood cell distribution width, GRACE score: The Global Registry of Acute Coronary Event risk score. 
Table 2: Cox regression analysis for $\mathrm{MACE}$ and cardiac death

\begin{tabular}{lcccc}
\hline Variable & Univariate HR (95\% CI) & $\boldsymbol{P}$-value & Multivariate HR (95\% CI) & $P$-value \\
\hline MACE & & & & \\
RDW & $1.697(1.449-1.988)$ & $<0.001$ & $1.735(1.439-2.091)$ & $<0.001$ \\
GRACE score & $1.020(1.015-1.025)$ & $<0.001$ & $1.022(1.017-1.028)$ & $<0.001$ \\
hsCRP & $1.076(1.045-1.108)$ & $<0.001$ & $1.056(1.025-1.088)$ & $<0.001$ \\
Current smoker & $1.302(0.918-1.846)$ & 0.139 & $1.668(1.166-2.387)$ & 0.005 \\
Anterior infarction & $1.366(0.963-1.937)$ & 0.080 & $1.673(1.163-2.407)$ & 0.006 \\
Killip class & $1.610(1.327-1.953)$ & $<0.001$ & - & - \\
Angina history & $0.756(0.488-1.171)$ & 0.210 & $0.522(0.329-0.829)$ & 0.006 \\
LDL-C & $1.215(0.970-1.522)$ & 0.090 & - & - \\
Cardiac death & & & & 0.002 \\
RDW & $1.534(1.208-1.948)$ & $<0.001$ & $1.562(1.174-2.078)$ & $<0.001$ \\
GRACE score & $1.016(1.008-1.024)$ & $<0.001$ & $1.015(1.007-1.023)$ & 0.024 \\
hsCRP & $1.072(1.025-1.120)$ & 0.002 & $1.054(1.007-1.103)$ & - \\
Killip class & $1.326(0.981-1.791)$ & 0.066 & & - \\
Anterior infarction & $2.184(1.257-3.794)$ & 0.006 & $2.221(1.268-3.892)$ & 0.005 \\
LDL-C & $1.563(1.126-2.169)$ & 0.008 & $1.499(1.092-2.059)$ & 0.012 \\
\hline
\end{tabular}

Abbreviations: HR: hazard ratio, CI: confidence interval, RDW: Red blood cell distribution width, GRACE score: The Global Registry of Acute Coronary Event risk score, hsCRP: Hypersensitive C reactive protein, LDL-C: Low-density lipoproteincholesterol, LVEDD: Left ventricular end-diastolic dimension.

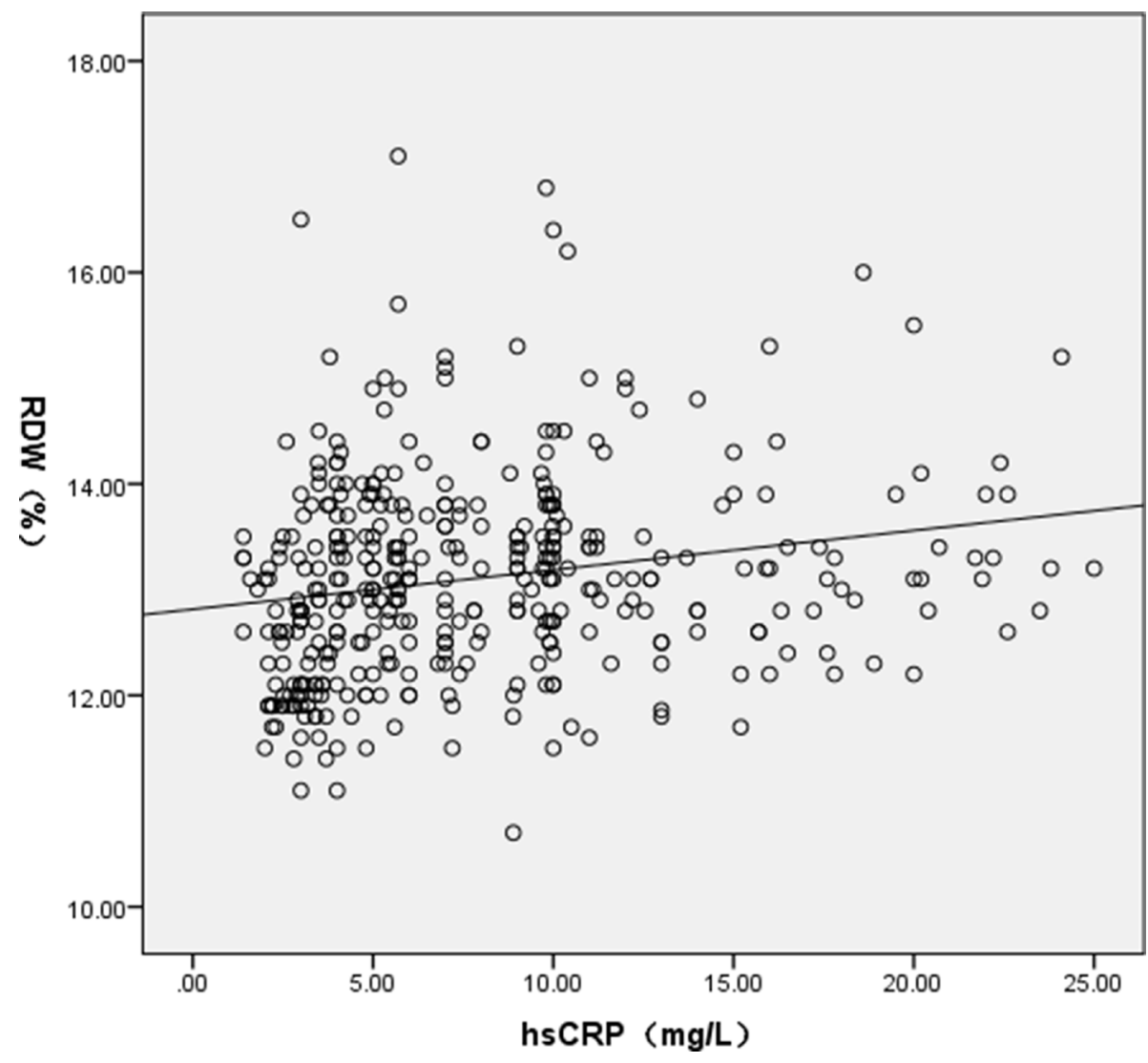

Figure 1: A scatter plot showing the relationship between RDW and hsCRP. RDW: Red blood cell distribution width, hsCRP: Hypersensitive $\mathrm{C}$ reactive protein. 
$13.25 \%)$ and high GRACE score $(<119.5)$ group $(n=93)$, high RDW $(>13.25 \%)$ and low GRACE score $(<119.5)$ group $(n=80)$, as well as high RDW $(>13.25 \%)$ and high GRACE score $(>119.5)$ group $(n=81)$. Result showed that patients with high RDW and high GRACE score had the worst outcomes. Correspondingly, Kaplan-Meier survival analysis revealed that the cumulative survival rate was the lowest in the high RDW and high GRACE score group (Log-Rank $\chi^{2}=24.684, P<0.001$ ) (Figure $3 \mathrm{~A})$. Significant intergroup differences $(p<0.001)$ were found between high RDW and high GRACE score group and all the rest groups as well as between high RDW and low GRACE score group and high RDW and low GRACE score group (Log-Rank $\chi^{2}=5.009, P=0.025$ ). Moreover, Kaplan-Meier survival analysis revealed that the cumulative survival rate free from Mace was the lowest in the high RDW and high GRACE score group (Log-Rank $\chi^{2}=92.252, P<0.001$ ) (Figure 3B).

\section{DISCUSSION}

The value of GRACE risk score in assessing prognosis and making treatment decisions has been clearly demonstrated in patients with ACS [13-14]. Current guidelines recommend its use for routine risk evaluation [15-16]. The predictive and prognostic value of RDW for adverse outcomes has also been demonstrated in patients with various diseases [4-10]. Subsequent studies have confirmed the significance of RDW level as an independent predictor for future cardiovascular events in ACS patients [17-18]. Ghaffari et al reported that an elevated baseline RDW could predict adverse outcomes in patients with STEMI undergoing thrombolytic therapy, during a follow-up period of $(7.7 \pm 3.2)$ months [19]. Isik et al studied the effects of RDW level on long-term prognosis in 96 STEMI patients who underwent primary PCI, and finally found that admission RDW level was an independent predictor of long term Mace [20]. To our knowledge, the main finding of our study is the first report showing the combined value of RDW and the GRACE score in predicting Mace at 36-month follow-up in patients with STEMI who underwent primary PCI.

The GRACE risk score models have been developed to predict risk within six months from discharge, and the models have been tested and validated in several studies and retained good predictive value for cardiovascular events up to five years in ACS patients $[13,21]$. Our study demonstrated that GRACE risk score can independently predict Mace and cardiac death at 36-month follow-up in STEMI patients undergoing primary PCI. However, both our current study and several previous studies found that this scoring system still needs to be improved [22-24]. The GRACE risk score system might have some limitation as various physiological and pathological processes, such as oxidative stress and inflammation, are not wholly covered by the system. Parenica et al study showed that

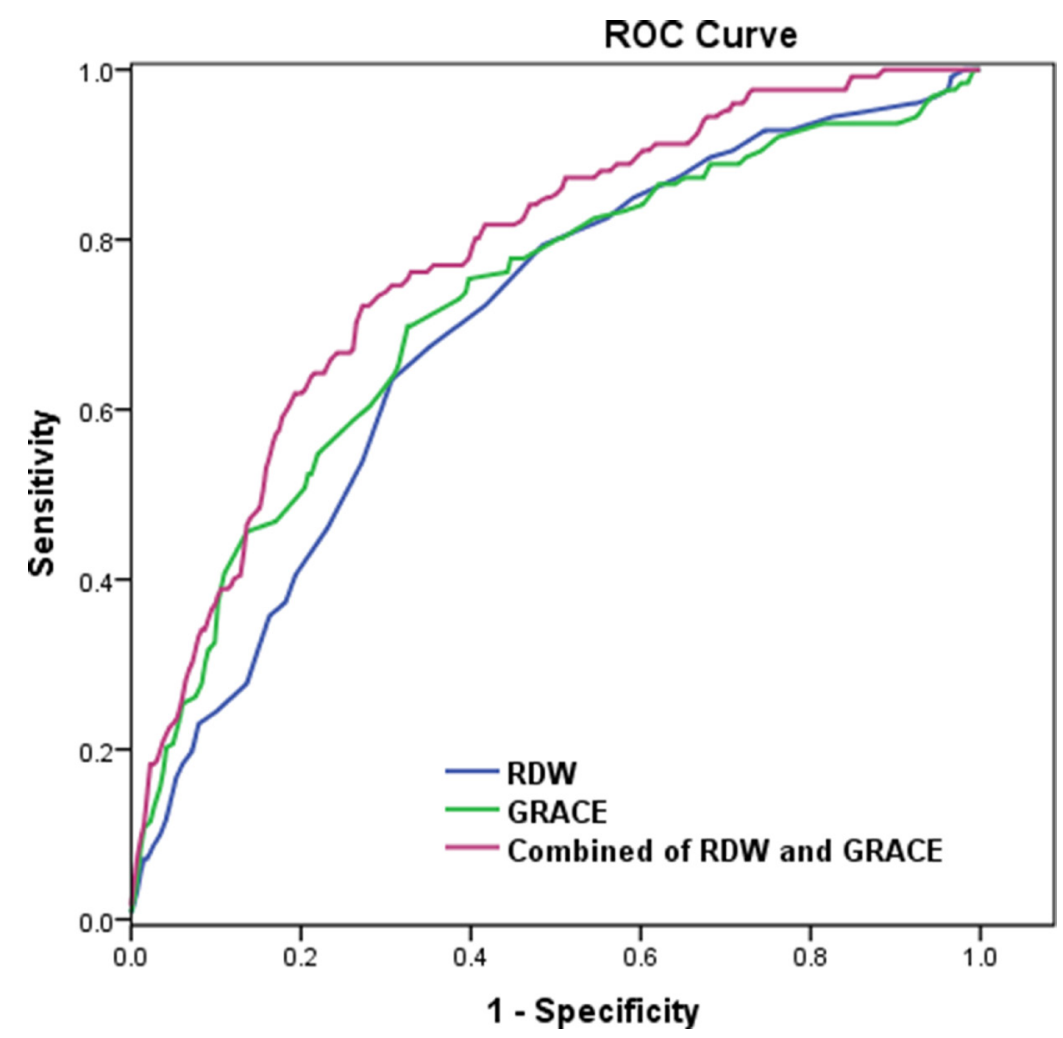

Figure 2: The receiver-operating characteristic (ROC) curve for red cell distribution width (RDW), GRACE score, and the combined value for predicting major adverse cardiac events (Mace) (Figure 2). 
combinations of oxidative stress parameters including Nitrite/nitrate and superoxide dismutase with the GRACE score could enhance risk discrimination in patients with STEMI treated by primary PCI [22]. In the SPUM-ACS Biomarker Cohort study, 1892 ACS patients were enrolled at four Swiss university hospitals between 2009 and 2012. The primary composite endpoint including all-cause mortality and non-fatal recurrent myocardial infarction was achieved in all patients during 12-month follow-up. The study revealed that the inflammation biomarkers of hsCRP have an additional value to the prognostic properties of the GRACE score for the prediction of Mace [24]. Moreover, our study found that adding RDW to the GRACE risk score system could enhance the predictive power in patients with STEMI who underwent primary PCI.

The prognostic value of RDW for short-term or long-term cardiovascular events have been demonstrated in STEMI patients $[20,25]$. In a meta-analysis involving 80216 patients from 22 studies, RDW was a remarkably strong predictor of all-cause mortality $(\mathrm{HR}=1.80,95 \%$ CI:1.35-2.41, $P<0.001)$ and non-fatal adverse events $(\mathrm{HR}=1.86,95 \% \mathrm{CI}: 1.50-2.31, P<0.001)$, although there was significant heterogeneity in the different studies [26]. In our study, the RDW level and GRACE score of Mace group are higher than those of non-Mace group. According to Univariate and multivariate Cox regression analyses, RDW and GRACE score were found to be the independent predictors of cardiovascular events in long-term follow-up, which was consistent with the results of previous studies [20, 21]. In addition, our study also found that RDW was highly associated with the risk of Mace and cardiac death in STEMI patients who underwent primary PCI. The Kaplan-Meier analysis revealed that RDW and GRACE score can be important

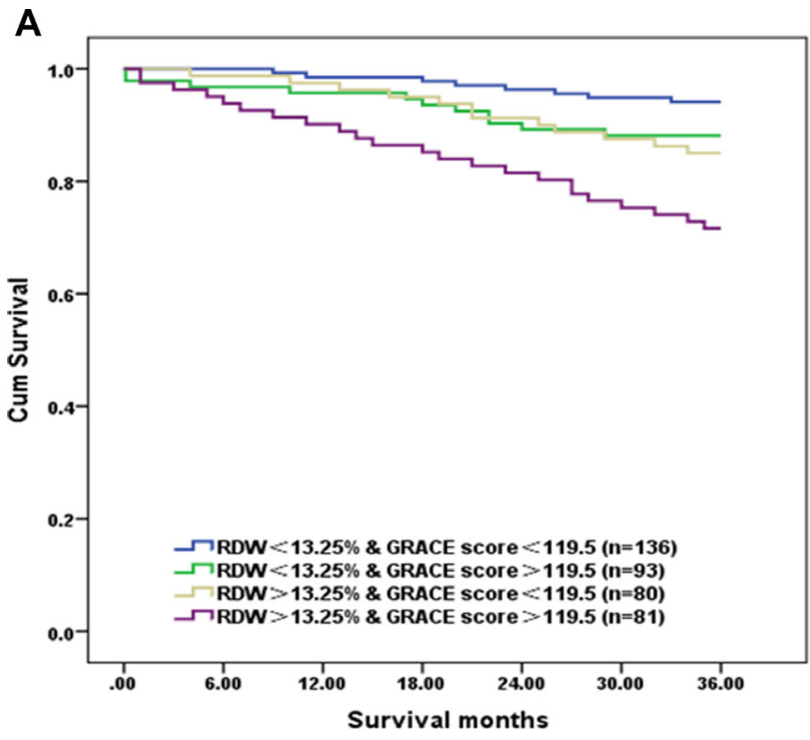

prognostic markers of negative long-term outcomes. Moreover, these results confirmed that RDW added discriminatory predictive value to the GRACE score. This added value was shown by the significant increase in AUC from 0.722 to 0.775 for the Mace during followup. Therefore, the combination of RDW and GRACE score could help evaluate long-term cardiovascular risk and could also provide an opportunity for early interventions to improve the prognosis in patients with STEMI who underwent primary PCI.

Exact physiological mechanisms between RDW and cardiovascular outcomes are not clearly understood. Several previous studies suggest that the level of RDW may reflect the extent oxidative stress, chronic subclinical inflammation, and lipid abnormalities [1, 27, 28]. Similar to previous studies [29], a significant positive correlation between hsCRP and RDW was established in our study, which indicating that RDW was significantly related to the inflammatory response intensity in STEMI patients undergoing primary PCI. Additionally, oxidative stress and inflammation result in disorders of iron metabolism and decrease the production of and response to erythropoietin, which thus might contribute to an increased RDW level [1, 27]. However, contrary to previous studies [28], our data failed to find the correlation between RDW and lipids. Neither have other authors found an association between RDW and lipids [30].

Despite that personalization therapy was recommended in high risk patients, new antiatherosclerotic therapies were still lack in current clinical practice. Our results may have potential implications for improved prediction and development of novel therapies if confirmed in independent larger studies in future.

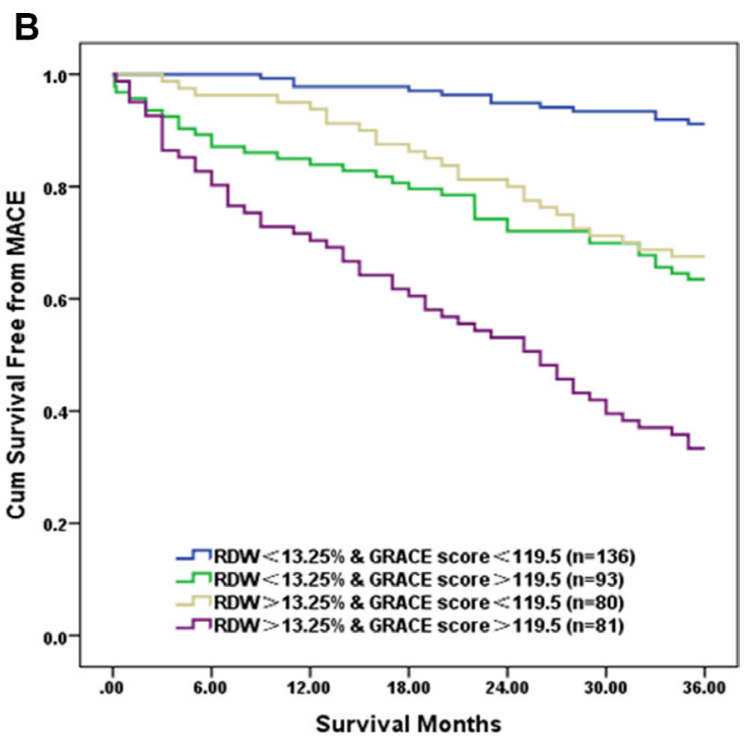

Figure 3: Kaplan-Meier survival analysis for cardiac death (A) and Mace (B). All patients were stratified into 4 groups based on cut-off values of RDW (13.25\%) and GRACE score (119.5). The group with high RDW ( $>13.25 \%)$ and high GRACE score ( $>119.5)$ had the worse prognosis than other groups (Log-Rank $\left.\chi^{2}=24.684,92.252, P<0.001\right)$. RDW: Red blood cell distribution width, GRACE score: The Global Registry of Acute Coronary Event risk score, Mace: major adverse cardiac events. 


\section{MATERIALS AND METHODS}

\section{Study population}

During the period from May 2012 until May 2014, a total of 390 STEMI patients were recruited in Luoyang central hospital affiliated to Zhengzhou University. All patients undergoing primary PCI within less than $12 \mathrm{~h}$ after the onset of symptoms. There were 295 males and 95 females among these patients. The average age was about $(55.25 \pm 6.79)$ years. All patients received loading doses of clopidogrel $(600 \mathrm{mg})$ and aspirin $(300 \mathrm{mg})$ before primary PCI and admitted to the coronary care unit after the surgery. Daily clopidogrel $(75 \mathrm{mg})$ and aspirin $(100 \mathrm{mg})$ were continued. STEMI is a syndrome defined as a typical chest pain of ischemia in association with persistent electrocardiographic ST elevation or new onset of complete left bundle branch block, and subsequent increasing of biomarkers of myocardial necrosis. Patients were excluded from the present study if they had history of revascularization, cardiomyopathies, valvular heart disease, chronic pulmonary disease, chronic renal failure, untreated infection, thyroid disease or previous myocardial infarction.

\section{Study parameters}

The current study is a prospective study approved by the Ethics Committee of Luoyang central hospital affiliated to Zhengzhou University. All patients underwent coronary angiography performed by the experienced interventional cardiologists who had no knowledge of the patients' clinical information. Each coronary artery was displayed in at least two different plane images using standard Judkins technique. The degree of coronary artery stenosis was determined by diameter method. Stenosis over $50 \%$ was defined as meaningful lesions. Gensini Score was used to determine the severity of coronary lesions according to the method described previously [31]. The Killip classification was based on the physical examination and the development of heart failure in order to predict and stratify the risk of mortality. All patients were classified in the following way: Killip class I, no clinical sign of heart failure. Killip class II, rales or crackles in the lungs, an S3 and elevated jugular venous pressure. Killip class III, acute pulmonary edema. Killip class IV, systolic blood pressure lower than $90 \mathrm{mmHg}$, cardiogenic shock. The GRACE risk score was calculated by the following variables [13], including age, heart rate, systolic blood pressure, creatinine, in-hospital PCI, STsegment depression, elevated cardiac enzyme, history of myocardial infarction, and congestive heart failure (http:// www.outcomes-umassmed.org).

The baseline data was collected in all cases, including gender, age, body mass index (BMI), current smoker, family history, hypertension, diabetes mellitus, angina history, anterior infarction, initial heart rate, and medication at discharge. On admission, white blood cell count (WBC), RDW, hemoglobin (HGB), platelet count $(\mathrm{PLT})$, potassium $\left(\mathrm{K}^{+}\right)$, creatinine $(\mathrm{Cr})$ and uric acid (UA) were measured before the coronary angiography. In addition, the levels of total cholesterol (TC), highdensity lipoprotein-cholesterol (HDL-C), low-density lipoprotein-cholesterol (LDL-C), triglyceride (TG) and hypersensitive $\mathrm{C}$ reactive protein (hSCRP) were obtained from fasting blood of the morning after admission. Blood was routinely measured by Sysmex XE2100 hematology analyzer and Beckman AU680 automated chemistry analyzer in the central laboratory of our hospital. Philips IE33 color Doppler ultrasound was employed to measure left ventricular end-diastolic dimension (LVEDD) and left ventricular ejection fraction (LVEF).

\section{Clinical outcomes and data collection}

All patients are routinely followed up for 36 months since their first admission. Clinical follow-up was carried out through patient visits. We reviewed the medical records if patient had readmitted to hospital. To minimize the loss to follow-up, we interviewed patients or their close relatives by telephone. Ultimately, Follow-up was $100 \%$ complete. The primary endpoints were defined as major adverse cardiac event (Mace), including cardiac death and nonfatal myocardial infarction (typical chest pain of ischemia in association with ST segment deviation, and subsequent increasing of biomarkers of myocardial necrosis). Sudden unexpected death was classified as cardiac death when it occurred outside the hospital.

\section{Statistical analysis}

All analyses were performed using Software IBM SPSS statistics for windows version 23 (IBM Corp., Armonk, NY). Continuous variables were expressed as mean \pm standard deviation (SD). The normality of data was examined. If data conformed to normality, group comparisons would be performed by independent samples $t$ test. If not, nonparametric test would be employed. Categorical variables were expressed as percentages and were compared by $\chi 2$ test. Associations between continuous variables were assessed by Pearson test. Univariate and multivariate Cox regression analyses were used to identify the relative risks (hazard ratio [HR]) for death and Mace associated with clinical risk factors, demographic and angiographic variables, such as gender, age, BMI, current smoker, angina history, hypertension, diabetes mellitus, family history, anterior infarction, Killip class, medication at discharge, HGB, PLT, total cholesterol, triglyceride, HDL-C, LDL-C, potassium, creatinine, uric acid, LVEDD, LVEF, Gensini score, number of diseased vessels and stents per patient, as well as with GRACE score, hsCRP and RDW levels. 
Receiver operating characteristic (ROC) curves was to ensure the best possible risk categorization. We also generated ROC curves to determine the sensitivities and specificities of hsCRP, GRACE score and RDW. Then, based on the cut-off values, patient outcomes were assessed using Kaplan-Meier survival curves with Logrank test. A two-tailed, $P$ value $<0.05$ was regarded as statistically significant.

\section{Limitations}

The current study has several potential limitations. Firstly, without wholly understanding of the detailed mechanisms linking the increased cardiovascular events in patients to higher levels of RDW, it seems to be too early to name RDW as a prognostic predictor in STEMI patients undergoing primary PCI. Secondly, it was a single-center real-world study that included a relatively small number of Chinese individuals. Multicenter studies may provide different insight. Thirdly, the cut-off value of RDW in the current study is $13.2 \%$. Several previous studies have also confirmed the significance of RDW level as an independent predictor for future cardiovascular events in ACS patients but the cut-off values are not the same $[32,33]$, making assess comparability between studies more complex. It might attribute to different diseases the patients suffering from, as ACS includes unstable angina, STEMI as well as non ST-segment elevation myocardial infarction (USTEMI). Additionally, different genetic background of the participants might also influence the level of RDW. Another potential reason is the type of hematology analyzer used. Blood in the current study was measured by Sysmex XE2100 hematology analyzer and Beckman AU680 automated chemistry analyzer in the central laboratory of our hospital. Because each device has a unique calibration and therefore it could affect the comparability of results.

\section{CONCLUSIONS}

The present study showed that combination of RDW level and GRACE score may be valuable and simple independent predictor for Mace and cardiac death in patients with STEMI who underwent primary PCI. They may be useful tools for risk stratification and may indicate long-term clinical outcomes. Our results may have potential implications for improved prediction and development of novel therapies. More studies with largerscale population are needed to validate the prognostic significance.

\section{CONFLICTS OF INTEREST}

The authors declare no conflicts of interest.

\section{FUNDING}

This study was supported by the Science and Technology project of Luoyang City (NO.1721001A-4) and the project of Henan Science and Technology (NO.122300410234).

\section{REFERENCES}

1. Danese E, Lippi G, Montagnana M. Red blood cell distribution width and cardiovascular diseases. J Thorac Dis. 2015; 7:E402-11.

2. Alcaíno H, Pozo J, Pavez M, Toledo H. Red cell distribution width as a risk marker in patients with cardiovascular diseases. [Article in Spanish] Rev Med Chil. 2016; 144:634-42.

3. Mallikethi-Reddy S, Briasoulis A, Akintoye E, Afonso L. Novel biomarkers with potential for cardiovascular risk reclassification. Biomarkers. 2017; 22:189-99. https://doi. org/10.1080/1354750X.2016.1201540.

4. Veeranna V, Zalawadiya SK, Panaich S, Patel KV, Afonso L. Comparative analysis of red cell distribution width and high sensitivity C-reactive protein for coronary heart disease mortality prediction in multi-ethnic population: findings from the 1999-2004 NHANES. Int J Cardiol. 2013; 168:5156-61. https://doi.org/10.1016/j.ijcard.2013.07.109.

5. Aung N, Ling HZ, Cheng AS, Aggarwal S, Flint J, Mendonca M, Rashid M, Kang S, Weissert S, Coats CJ, Richards T, Thomas M, Woldman S, Okonko DO. Expansion of the red cell distribution width and evolving iron deficiency as predictors of poor outcome in chronic heart failure. Int J Cardiol. 2013; 168:1997-2002. https:// doi.org/10.1016/j.ijcard.2012.12.091.

6. Shao Q, Li L, Li G, Liu T. Prognostic value of red blood cell distribution width in heart failure patients: a meta-analysis. Int J Cardiol. 2015; 179:495-99. https://doi.org/10.1016/j. ijcard.2014.11.042.

7. Saliba W, Barnett-Griness O, Rennert G. Red cell distribution width and all-cause mortality in patients with atrial fibrillation: A cohort study. J Arrhythm. 2017; 33:5662. https://doi.org/10.1016/j.joa.2016.06.001.

8. Duchnowski P, Szymański P, Orłowska-Baranowska E, Kuśmierczyk M, Hryniewiecki T. Raised red cell distribution width as a prognostic marker in aortic valve replacement surgery. Kardiol Pol. 2016; 74:547-52.

9. Yazıcı S, Kırış T, Sadık Ceylan U, Terzi S, Uzun AO, Emre A, Yeşilçimen K. Relation between dynamic change of red cell distribution width and 30-day mortality in patients with acute pulmonary embolism. Clin Respir J. 2017 Jan 7. [Epub ahead of print].

10. Siegler JE, Marcaccio C, Nawalinski K, Quattrone F, Sandsmark DK, Maloney-Wilensky E, Frangos S, Levine JM, Stein SC, Kasner SE, Kumar MA. Elevated Red Cell Distribution Width is Associated with Cerebral Infarction 
in Aneurysmal Subarachnoid Hemorrhage. Neurocrit Care. 2017; 26:26-33. https://doi.org/10.1007/s12028-016-0306-2.

11. Duchnowski P, Hryniewiecki T, Kusmierczyk M, Szymanski P. Red cell distribution width is a prognostic marker of perioperative stroke in patients undergoing cardiac valve surgery. Interact Cardiovasc Thorac Surg. 2017; 25:925-29. https://doi.org/10.1093/icvts/ivx216.

12. Lee JH, Yang DH, Jang SY, Choi WS, Kim KH, Lee WK, Bae MH, Park HS, Cho Y, Chae SC. Incremental predictive value of red cell distribution width for 12-month clinical outcome after acute myocardial infarction. Clin Cardiol. 2013; 36:336-41. https://doi.org/10.1002/clc.22114.

13. Granger CB, Goldberg RJ, Dabbous O, Pieper KS, Eagle KA, Cannon CP, Van De Werf F, Avezum A, Goodman SG, Flather MD, Fox KA, and Global Registry of Acute Coronary Events Investigators. Predictors of hospital mortality in the global registry of acute coronary events. Arch Intern Med. 2003; 163:2345-53. https://doi. org/10.1001/archinte.163.19.2345.

14. Bradshaw PJ, Katzenellenbogen JM, Sanfilippo FM, Hobbs MS, Thompson PL, Thompson SC. Validation study of GRACE risk scores in indigenous and non-indigenous patients hospitalized with acute coronary syndrome. BMC Cardiovasc Disord. 2015; 15:151. https://doi.org/10.1186/ s12872-015-0138-6.

15. Roffi M, Patrono C, Collet JP, Mueller C, Valgimigli M, Andreotti F, Bax JJ, Borger MA, Brotons C, Chew DP, Gencer B, Hasenfuss G, Kjeldsen K, et al. 2015 ESC Guidelines for the management of acute coronary syndromes in patients presenting without persistent STsegment elevation: Task Force for the Management of Acute Coronary Syndromes in Patients Presenting without Persistent ST-Segment Elevation of the European Society of Cardiology (ESC). Eur Heart J. 2016; 37:267-315. https:// doi.org/10.1093/eurheartj/ehv320.

16. Levine GN, Bates ER, Blankenship JC, Bailey SR, Bittl JA, Cercek B, Chambers CE, Ellis SG, Guyton RA, Hollenberg SM, Khot UN, Lange RA, Mauri L, et al. 2015 ACC/AHA/ SCAI focused update on primary percutaneous coronary intervention for patients with ST-elevation myocardial infarction: an update of the 2011 ACCF/AHA/SCAI guideline for percutaneous coronary intervention and the 2013 ACCF/AHA guideline for the management of ST-elevation myocardial infarction: a report of the American College of Cardiology/American Heart Association Task Force on Clinical Practice Guidelines and the Society for Cardiovascular Angiography and Interventions. Circulation. 2016; 133:113547. https://doi.org/10.1161/CIR.0000000000000336.

17. Rosas-Cabral A, Viana-Rojas JA, Prieto-Macías J, del Carmen Terrones-Saldívar M, Gutiérrez-Campos R, Ponce-Campos SD, de Jesús de Lara-Castañeda J. The association between red cell distribution width (RDW) and short-term mortality risk in patients with acute coronary syndrome (ACS). [Article in Spanish] Gac Med Mex. 2016; 152:70-77.
18. Turcato G, Serafini V, Dilda A, Bovo C, Caruso B, Ricci G, Lippi G. Red blood cell distribution width independently predicts medium-term mortality and major adverse cardiac events after an acute coronary syndrome. Ann Transl Med. 2016; 4:254. https://doi.org/10.21037/atm.2016.06.35.

19. Ghaffari S, Pourafkari L, Sepehrvand N, Aslanabadi N, Faridi L, Tajlil A, Masoumi N, Nader ND. Red cell distribution width is a predictor of ST resolution and clinical outcome following thrombolysis in acute ST elevation myocardial infarction. Thromb Res. 2016; 140:1-6. https:// doi.org/10.1016/j.thromres.2016.02.008.

20. Isik T, Kurt M, Tanboga IH, Ayhan E, Gunaydin ZY, Kaya A, Uyarel H. The impact of admission red cell distribution width on long-term cardiovascular events after primary percutaneous intervention: A four-year prospective study. Cardiol J. 2016; 23:281-88. https://doi.org/10.5603/ CJ.a2015.0080.

21. Zhao N, Mi L, Liu X, Pan S, Xu J, Xia D, Liu Z, Zhang Y, Xiang Y, Yuan Z, Guan G, Wang J. Combined Value of Red Blood Cell Distribution Width and Global Registry of Acute Coronary Events Risk Score for Predicting Cardiovascular Events in Patients with Acute Coronary Syndrome Undergoing Percutaneous Coronary Intervention. PLoS One. 2015; 10:e0140532. https://doi.org/10.1371/journal. pone. 0140532 .

22. Parenica J, Kala P, Pavkova MG, Tomandl J, Spinar J, Littnerova S, Jarkovsky J, Mebazaa A, Tomandlova M, Dastych M, Gottwaldova J, Gayat E. Natriuretic peptides, nitrite/nitrate and superoxide dismutase have additional value on top of the GRACE score in prediction of one-year mortality and rehospitalisation for heart failure in STEMI patients - Multiple biomarkers prospective cohort study. Int J Cardiol. 2016; 211:96-104. https://doi.org/10.1016/j. ijcard.2016.02.135.

23. Liu XJ, Wan ZF, Zhao N, Zhang YP, Mi L, Wang XH, Zhou D, Wu Y, Yuan ZY. Adjustment of the GRACE score by HemoglobinA1c enables a more accurate prediction of long-term major adverse cardiac events in acute coronary syndrome without diabetes undergoing percutaneous coronary intervention. Cardiovasc Diabetol. 2015; 14:110. https://doi.org/10.1186/s12933-015-0274-4.

24. Klingenberg R, Aghlmandi S, Räber L, Gencer B, Nanchen D, Heg D, Carballo S, Rodondi N, Mach F, Windecker S, Jüni P, von Eckardstein A, Matter CM, Lüscher TF. Improved risk stratification of patients with acute coronary syndromes using a combination of hsTnT, NT-proBNP and hsCRP with the GRACE score. Eur Heart J Acute Cardiovasc Care. 2016 Dec 1. [Epub ahead of print].

25. Khaki S, Mortazavi SH, Bozorgi A, Sadeghian S, Khoshnevis M, Mahmoodian M. Relationship Between Red Blood Cell Distribution Width and Mortality of Patients with Acute Myocardial Infarction Referring to Tehran Heart Center. Crit Pathw Cardiol. 2015; 14:112-15. https://doi. org/10.1097/HPC.0000000000000047. 
26. Su C, Liao LZ, Song Y, Xu ZW, Mei WY. The role of red blood cell distribution width in mortality and cardiovascular risk among patients with coronary artery diseases: a systematic review and meta-analysis. J Thorac Dis. 2014; 6:1429-40.

27. Balta S, Demirkol S, Aparci M, Arslan Z, Ozturk C. Red Cell Distribution Width in Myocardial Infarction. Med Princ Pract. 2015; 24:584-85. https://doi.org/10.1159/000437355.

28. Lippi G, Sanchis-Gomar F, Danese E, Montagnana M. Association of red blood cell distribution width with plasma lipids in a general population of unselected outpatients. Kardiol Pol. 2013; 71:931-36. https://doi.org/10.5603/ KP.2013.0228.

29. Doğan S, Atakan N. Red Blood Cell Distribution Width is a Reliable Marker of Inflammation in Plaque Psoriasis. Acta Dermatovenerol Croat. 2017; 25:26-31.

30. Vayá A, Sarnago A, Fuster O, Alis R, Romagnoli M. Influence of inflammatory and lipidic parameters on red blood cell distribution width in a healthy population. Clin Hemorheol Microcirc. 2015; 59:379-85. https://doi. org/10.3233/CH-141862.
31. Gensini GG. A more meaningful scoring system for determining the severity of coronary heart disease. Am J Cardiol. 1983; 51:606. https://doi.org/10.1016/S00029149(83)80105-2.

32. Cavusoglu E, Chopra V, Gupta A, Battala VR, Poludasu $\mathrm{S}$, Eng C, Marmur JD. Relation between red blood cell distribution width (RDW) and all-cause mortality at two years in an unselected population referred for coronary angiography. Int J Cardiol. 2010; 141:141-46. https://doi. org/10.1016/j.ijcard.2008.11.187.

33. Bekler A, Tenekecioğlu E, Erbağ G, Temiz A, Altun B, Barutçu A, Gazi E, Güneş F, Yılmaz M. Relationship between red cell distribution width and long-term mortality in patients with non-ST elevation acute coronary syndrome. Anatol J Cardiol. 2015; 15:634-39. https://doi.org/10.5152/ akd.2014.5645. 